\title{
三江源区典型高寒草甸土壤侵蚀的 ${ }^{137} \mathrm{Cs}$ 定量分析
}

邵全琴 $^{(1)}$, 肖桐 ${ }^{(1)}$ ，刘纪远 ${ }^{(1 *}$ ，齐永青 ${ }^{(3)}$

(1) 中国科学院地理科学与资源研究所, 北京 100101 ;

(2) 中国科学院研究生院, 北京 100049 ;

(3) 中国科学院遗传与发育生物学研究所农业资源研究中心, 石家庄 050021

* 联系人, E-mail: liujy@igsnrr.ac.cn

2010-06-19 收稿, 2010-11-05 接受

国家重点基础研究发展计划(2009CB421105)、中国科学院西部行动计划(KZCX2-XB2-06-03)和国家科技支撑计划(2006BAC08B00)资助 项目

摘要 高寒草甸是青海三江源地区的主体生态系统. 高寒草甸的根系盘结, 形成坚实的“地毯 式”草皮层，固土持水能力强，是维持“中华水塔”的主要贡献者. 为了定量分析典型高寒草甸的 抗侵蚀能力, 本文选择草皮层完整、植被覆盖度在 $60 \%$ 以上的典型高寒草甸坡面, 进行了土壤 侵蚀的 ${ }^{137} \mathrm{Cs}$ 核素示踪研究. 结果表明: (1) 各采样坡面土壤侵蚀强度属微度-轻度侵蚀水平, 玉 树县玛龙村坡面多年平均土壤侵蚀模数为 $464 \mathrm{t} \mathrm{km}^{-2} \mathrm{a}^{-1}$, 玛多县野牛沟乡坡面为 $415 \mathrm{t} \mathrm{km}^{-2} \mathrm{a}^{-1}$,

关键词

三江源

土壤侵蚀

高寒草甸

${ }^{137} \mathrm{Cs}$ 核素示踪 称多县珍秦乡坡面为 $875 \mathrm{t} \mathrm{km}^{-2} \mathrm{a}^{-1}$. (2) 在坡面尺度上, 土壤侵蚀速率与植被覆盖度呈负相关, 植被覆盖度越高, 坡面侵蚀模数越小 $\left(P<0.01, R^{2}=0.986\right)$; 在样点尺度上, 土壤侵蚀速率与植被 覆盖度之间也具有较好的负相关关系 $\left(P<0.01, R^{2}=0.555\right)$. (3) 三江源地区高寒草甸坡面侵蚀强 度及其与植被覆盖度的关系表明, 植被是土壤侵蚀的最主要影响因素之一, 具有完整草皮层且 植被覆盖度较高的高寒草甸, 对于土壤保护和防止水土流失具有重要的意义。

${ }^{137} \mathrm{Cs}$ 是 20 世纪 50 70 年代各国进行大气层核试 验产生的放射性核素，半衰期 30.17 a，主要随降雨 沉降到地面, 被土壤颗粒和有机质强烈吸附, 基本不 被植物吸收或淋溶损失，因此某一地点 ${ }^{137} \mathrm{Cs}$ 赋存量 的减少只与衰变和伴随土壤颗粒被侵蚀流失有关 ${ }^{[1 \sim 3]}$. 利用侵蚀或堆积地点的 ${ }^{137} \mathrm{Cs}$ 赋存量与土壤侵蚀或堆 积量的相关关系, 可建立简单的数学模型, 然后通过 测定 ${ }^{137} \mathrm{Cs}$ 在地表垂直剖面和水平断面赋存量的变化 和空间分布, 就可以测定不同地点的土壤侵蚀或堆 积速率. 因此 ${ }^{137} \mathrm{Cs}$ 是研究土壤侵蚀的良好示踪剂. 自 20 世纪 70 年代以来, 国内学者利用 ${ }^{137} \mathrm{Cs}$ 核素示 踪方法在不同研究区已经取得了丰硕的成果。如利 用 ${ }^{137} \mathrm{Cs}$ 核素示踪方法在黄土高原上开展的土壤侵蚀 定量研究 ${ }^{[4]}$; 在小流域尺度上对土壤侵蚀与沉积的空 间分布特征的描述以及不同土地利用方式下土壤侵
蚀强度的比较 ${ }^{[5,6]}$; 对长江上游不同土地利用类型以 及重点水土流失区坡耕地土壤侵蚀速率的定量研 究 $^{[7,8]}$; 对黑土区土壤侵蚀和沉积特征的应用 ${ }^{[9]}$; 测 定了土质黏重的红壤区 ${ }^{137} \mathrm{Cs}$ 的剖面分布 ${ }^{[10]}$; 开展了 红壤丘陵区坡地不同土地利用类型的土壤侵蚀研 究 $^{[11]}$. 除以上研究区外, 对青藏高原地区也开展了 大量的 ${ }^{137} \mathrm{Cs}$ 核素示踪研究工作, 但是这些研究多是 集中在沙地、风蚀草地、沙丘等生态系统类型上的风 蚀研究 ${ }^{[12 ~ 15]}$, 类似的研究也出现在蒙古高原的草地 样带上 ${ }^{[16 ~ 18]}$.

在青海达日县的研究 ${ }^{[19]}$ 包含了部分水蚀的成分, 但是并没有深人到青藏高原腹地的典型高寒草甸开 展工作. 从目前的研究看, 虽然研究区遍及黄土高原、 长江中上游、东北黑土区、南方红壤区以及青藏高原, 但是在除青藏高原以外的地区, 研究对象多以水蚀 
为主, 在青藏高原开展的研究又多在高原东部, 且多 以风蚀为主要研究对象, 深人高原腹地开展典型高 寒草甸的水蚀研究不多. 另一方面青海三江源地区 地处青藏高原腹地, 是长江、黄河、澜沧江三大河流 的发源地, 拥有世界上海拔最高(平均海拔 $4400 \mathrm{~m}$ )、 面积最大的高原湿地生态系统，包括河流、湖泊、沼 泽、雪山、冰川等多种湿地类型，也是世界上高海拔 地区生物多样性最集中的地区之一. 草地是该区域 的主体生态系统, 占全区总面积的 $65.37 \%{ }^{[20]}$, 高寒 草甸是其主要的草地类型，占全区草地面积的 $76 \%$. 高寒草甸的根系盘结，形成坚实的“地毯式”草皮层， 耐践踏, 固土持水能力强, 是维持三江源区“中华水 塔”的主要贡献者之一. 因此在“三江源”地区定量分 析典型高寒草甸的抗侵蚀能力, 尤其是在长江流域、 黄河流域、澜沧江源头流域选择草皮层完整、植被覆 盖度较高的典型高寒草甸坡面进行 ${ }^{137} \mathrm{Cs}$ 定量分析对 于揭示高寒草甸生态系统的保土保水功能具有十分 重要的指导意义.

\section{1 研究区概况}

采样坡面分别位于黄河流域玛多县、长江流域称 多县和澜沧江流域玉树县, 各采样坡面均为高原低 地地貌, 平均海拔大于 $4200 \mathrm{~m}$, 植被类型为高寒草 甸, 土壤为草䏨土. 研究区气候为典型的高原大陆性气 候, 冷热两季交替、干湿两季分明、日照时间长、辐射 强烈. 玛多县年均温度为 $-3.76^{\circ} \mathrm{C}$, 年降水量为 316 $\mathrm{mm}$; 称多县年均温度为 $-4.66^{\circ} \mathrm{C}$, 年降水量为 $508 \mathrm{~mm}$; 玉树县年均温度为 $3.29^{\circ} \mathrm{C}$, 年降水量为 $479 \mathrm{~mm}$.

\section{2 数据与方法}

\section{1 样品采集与分析}

土壤样品于 2008 年 7 月采集(图 1 和表 1), 双坡 面线法采样，在坡面上沿顺坡方向间隔 15 30 m 布设 两条平行坡面线, 按一定间隔, 设置 7 9 个采样点. 考虑到 ${ }^{137} \mathrm{Cs}$ 在草原(草甸)土壤中分布较浅, 一般在 $15 \mathrm{~cm}$ 以内的实际情况 ${ }^{[14,16 ~ 18]}$, 采样深度确定为 24 $\mathrm{cm}$. 全样使用直径 $90 \mathrm{~mm}$ 土钻, 采集 $0 \sim 24 \mathrm{~cm}$ 深的土 样; 在每个坡面的中部, 选择典型地点, 使用 $18 \mathrm{~cm}$ $\times 25 \mathrm{~cm}$ 采样框采集分层样; 分层深度为 $0 \sim 2,2 \sim 4$, 4 6, 6 8, 8 12, 12 18 和 18 24 cm. 土壤容重样品采 用环刀法, 每个坡面 5 个重复. 植被组成、盖度、高 度和生物量通过样方调查获取.

土壤样品经风干、研磨后, 过 $2 \mathrm{~mm}$ 篎, 去除植 物残体和砾石. 取粒径小于 $2 \mathrm{~mm}$ 样品 $>250 \mathrm{~g}$ 进行 ${ }^{137} \mathrm{Cs}$ 活度的测定. 样品测试由中国地质大学辐射与环 境实验室完成, 采用美国 Ametek 公司的 ORTEC 高纯 锗 $\gamma$ 能谱测量系统(HPGe, Despec), 计算 $662 \mathrm{KeV} \gamma$ 射 线的全峰面积, 从而获得土样的 ${ }^{137} \mathrm{Cs}$ 活度. 该 $\gamma$ 谱仪 的相对探测效率为 $30 \%$, 对 ${ }^{60} \mathrm{Co} 1.33 \mathrm{MeV}$ 的能量分 辨率为 $1.67 \mathrm{keV}$, 由于自然界中不存在 ${ }^{137} \mathrm{Cs}$ 的分布, 仪器的 ${ }^{137} \mathrm{Cs}$ 的探测下限接近 $0.77 \mathrm{~Bq} / \mathrm{kg}$, 样品的测试 累积时间为 $11033 \sim 38100 \mathrm{~s}$, 对检测出 ${ }^{137} \mathrm{Cs}$ 活度 $>0$ 的样品的累积测试时间均大于 $15000 \mathrm{~s}$ 以上. 测试误 差控制标准为 $\pm 5 \%$ (可信度 $95 \%$ ).

\section{$2.2{ }^{137} \mathrm{Cs}$ 土壤侵蚀计算}

实验室测量得到的结果为基于单位质量的 ${ }^{137} \mathrm{Cs}$ 活度 $(\mathrm{Bq} / \mathrm{kg})$, 把此数据乘以土壤容重和厚度后, 可 以将其转换为基于面积的活度, 单位为 $\mathrm{Bq} / \mathrm{m}^{2}$. 采样

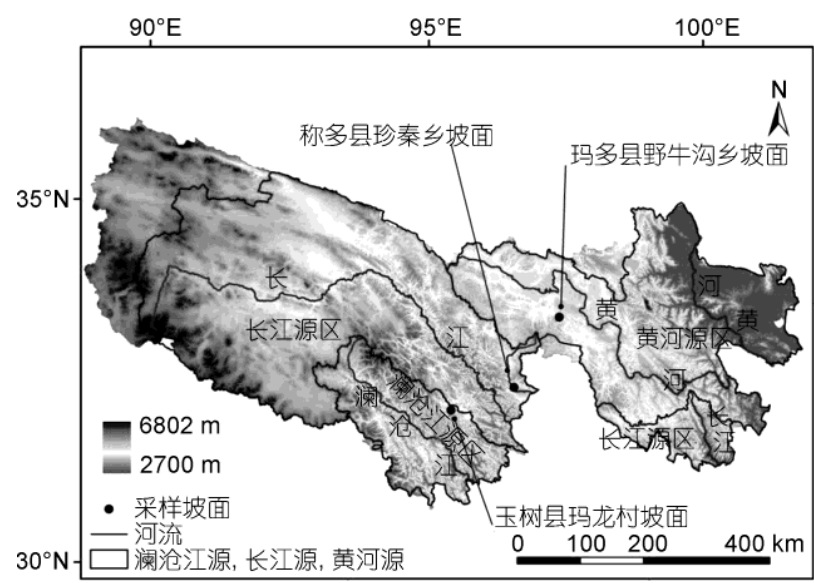

图 1 研究区地形及 ${ }^{137} \mathrm{Cs}$ 采样坡面分布图

表 $1{ }^{137} \mathrm{Cs}$ 采样点基本情况

\begin{tabular}{|c|c|c|c|c|c|c|c|c|c|}
\hline 样地编号 & 地名 & 所属流域 & 经纬度 & 海拔(m) & 土壤类型 & 坡向 & $\begin{array}{l}\text { 坡长 } \\
(\mathrm{m})\end{array}$ & $\begin{array}{c}\text { 土壤容重 } \\
\left(\mathrm{g} / \mathrm{cm}^{3}\right)\end{array}$ & $\begin{array}{c}\text { 植被平均 } \\
\text { 覆盖度 }\end{array}$ \\
\hline S1 & 玉树县玛龙村 & 澜沧江 & $32^{\circ} 58^{\prime} 25.3^{\prime \prime} \mathrm{N}, 96^{\circ} 19^{\prime} 01.1^{\prime \prime} \mathrm{E}$ & 4384 & 草轳土 & 正南 & 800 & 0.95 & $84 \%$ \\
\hline S2 & 称多县珍秦乡 & 长江 & $33^{\circ} 24^{\prime} 26.8^{\prime \prime} \mathrm{N}, 97^{\circ} 20^{\prime} 25.4^{\prime \prime} \mathrm{E}$ & 4350 & 草毡土 & 正东 & 330 & 0.84 & $70 \%$ \\
\hline S3 & 玛多县野牛沟乡 & 黄河 & $34^{\circ} 27^{\prime} 51.98^{\prime \prime} \mathrm{N}, 97^{\circ} 58^{\prime} 9.4^{\prime \prime} \mathrm{E}$ & 4430 & 草毡土 & 西北 & 245 & 0.74 & $88 \%$ \\
\hline
\end{tabular}


点 ${ }^{137} \mathrm{Cs}$ 总量的活度 $\left(\mathrm{Bq} / \mathrm{m}^{2}\right)$ 则是指从土壤表面到 ${ }^{137} \mathrm{Cs}$ 完全不可检测出深度之间的所有土层中 ${ }^{137} \mathrm{Cs}$ 面 积活度之和, 可采用以下公式计算 ${ }^{[21]}$ :

$$
\mathrm{CPI}=10^{3} \sum_{i=1}^{n} C_{i} \cdot B_{i} \cdot D_{i},
$$

式中, CPI 是样点的 ${ }^{137} \mathrm{Cs}$ 总量 $\left(\mathrm{Bq} / \mathrm{m}^{2}\right), i$ 为层序号, $n$ 为采样层数, $C_{i}$ 为第 $i$ 采样层中 ${ }^{137} \mathrm{Cs}$ 的活度 $(\mathrm{Bq} / \mathrm{kg})$, $B_{i}$ 为第 $i$ 采样层的土壤容重 $\left(\mathrm{t} / \mathrm{m}^{3}\right), D_{i}$ 为第 $i$ 采样层的 厚度 $(\mathrm{m})$.

国内外发展了很多利用 ${ }^{137} \mathrm{Cs}$ 活度求算土壤侵蚀 量的模型, 较为经典的是剖面分布模型 ${ }^{[22]}$. 该模型 基于非耕作土壤剖面 ${ }^{137} \mathrm{Cs}$ 的指数分布形式，同时假 定 ${ }^{137} \mathrm{Cs}$ 最大沉降于 1963 年. 该模型在实际应用中得 到了广泛认可.

但是考虑到 ${ }^{137} \mathrm{Cs}$ 随雨水降落地表后，迅速被表 层土壤吸附. 被土壤吸附的 ${ }^{137} \mathrm{Cs}$ 的运动与迁移与土 壤颗粒的运动有很大的关系. 虽然经典的剖面分布 模型在计算土壤侵蚀上得到了广泛的应用, 但是随 着时间的推移, 在非耕作土层中的 ${ }^{137} \mathrm{Cs}$ 分布由于纵 向的扩散过程使得剖面无法用简单的剖面形态模型 来描述. 基于 Walling 和 $\mathrm{He}^{[23]}$ 的侵蚀评价模型, Zhang 等人 ${ }^{[24]}$ 发展了一种基于 ${ }^{137} \mathrm{Cs}$ 传输扩散过程的 侵蚀评价模型, 进一步提高了侵蚀速率计算结果的 精度. 土壤侵蚀速率的计算方法为

$$
K=1-\mathrm{e}^{-h_{0} N H},
$$

式中, $K$ 是剖面中 ${ }^{137} \mathrm{Cs}$ 的相对流失量, 计算方法为 $K=\frac{A_{r m(T)}-A_{r e f(T)}}{A_{r e f(T)}} \times 100 \%$, 其中 $A_{r e f(T)}$ 是采样年本底 值 ${ }^{137} \mathrm{Cs}$ 含量 $\left(\mathrm{mBq} / \mathrm{cm}^{2}\right), A_{r m(T)}$ 是采样年剖面 ${ }^{137} \mathrm{Cs}$ 含 量 $\left(\mathrm{mBq} / \mathrm{cm}^{2}\right), H$ 为自 1963 年以来的年土壤侵蚀厚度 $(\mathrm{cm}), h_{0}$ 为 ${ }^{137} \mathrm{Cs}$ 剖面形态系数, $N$ 为被侵蚀的土壤层 数, 数值上等于 1963 年以来的时间.

\section{$2.3{ }^{137} \mathrm{Cs}$ 背景值确定}

${ }^{137} \mathrm{Cs}$ 背景值是指自 ${ }^{137} \mathrm{Cs}$ 沉降以来, 无侵蚀堆积 土壤剖面中的 ${ }^{137} \mathrm{Cs}$ 面积活度 ${ }^{[25]}$, 是保障土壤侵蚀模 数计算结果可靠性的重要基础. 本研究在 3 个采样坡 面附近分别采集了对应的本底值样品. 本底值采样 点均属典型高寒草甸, 地形平坦, 地表植被覆盖度 90\% 100\%, 无侵蚀和堆积作用发生, 植被根系层完 整, 厚度 12 16 cm, 根系致密. 每个坡面的本底样由 1 组分层样和 4 组全样组成, 采样方法与坡面样品采
集方法相同. 本底值分层样的 ${ }^{137} \mathrm{Cs}$ 剖面分布均呈典 型的在扩散作用影响下的指数曲线形态 ${ }^{[24,26]}$, 最大 ${ }^{137} \mathrm{Cs}$ 活度均明显高于对应的坡面分层样(图 2).

为进一步确定本研究测定的 ${ }^{137} \mathrm{Cs}$ 背景值的可靠 性, 我们将其与其他研究得到的三江源区域 ${ }^{137} \mathrm{Cs}$ 实 测背景值, Walling 与 $\mathrm{He}$ 的 ${ }^{137} \mathrm{Cs}$ 沉降模型的模拟值 进行了比较. 本研究 ${ }^{137} \mathrm{Cs}$ 背景值与严平等人 ${ }^{[12,13]}$ 、 张春来等人 ${ }^{[14,15]}$ 测定的青海共和盆地的背景值接近 (表 2), 明显低于李元寿等人 ${ }^{[19]}$ 在达日县测定的背景 值. 受模型中假设条件的影响, Walling 与 $\mathrm{He}$ 的 ${ }^{137} \mathrm{Cs}$ 沉降模型的模拟结果一般均低于实测值 ${ }^{[27]}$, 但通过 不同研究地点实测值与模拟结果的对比, 可以认为 除李元寿等人 ${ }^{[19]}$ 的达日县背景值明显偏高外, 包括 本研究 3 个地点的背景值在内的其他各点的背景值 均较为合理.

\section{3 结果分析}

\section{1 三江源典型高寒草甸坡面土壤侵蚀特征}

玛龙坡面位于澜沧江流域. 坡面草皮层较完整, 土壤为高寒草甸区典型的草毡土, $0 \sim 15 \mathrm{~cm}$ 为根系层, 其中 0 10 cm 层位根系集中盘结分布. 坡面土层较薄, 厚度 $18 \sim 30 \mathrm{~cm}$, 其下即为碎屑状的砾石坡积物. 坡 面植被覆盖良好, 平均盖度 $84 \%$, 高度 $2 \sim 5 \mathrm{~cm}$, 以小 嵩草、矮嵩草、珠牙苶等高寒草甸典型植物为主, 伴 生美丽风毛菊、麻花芜、雪白委陵菜、双柱头蔍草等.

玛龙坡面各个部位的侵蚀速率差异较大(表 3): 坡面上段坡度达 $10^{\circ}(\mathrm{S} 1-01 \sim \mathrm{S} 1-03)$, 除最上部 S1-01 点基本无侵蚀发生外, 侵蚀速率随距离坡顶距离的 增加而增大, $\mathrm{S} 1-03$ 点植被覆盖度为 $75 \%$, 为各样点 最低, 其侵蚀模数最大, 为 $945 \mathrm{t} \mathrm{km}^{-2} \mathrm{a}^{-1}$; 坡面中段 的坡度为 $5^{\circ}(\mathrm{S} 1-04 \sim \mathrm{S} 1-06)$, 侵蚀强度的差异不明显,

表 2 三江源地区典型草甸实测本底值与模拟值和附近区 域本底值的对比 ${ }^{\text {a) }}$

\begin{tabular}{ccccc}
\hline 样点 & $\begin{array}{c}\text { 降雨量 } \\
(\mathrm{mm})\end{array}$ & $\begin{array}{c}\text { 实测背景值 } \\
\left(\mathrm{Bq} / \mathrm{m}^{2}\right)\end{array}$ & $\begin{array}{c}\text { 模拟值 } \\
\left(\mathrm{Bq} / \mathrm{m}^{2}\right)\end{array}$ & 文献 \\
\hline 青海玉树县玛龙村 & 479 & 2130 & 1096 & 本文 \\
青海称多县珍秦乡 & 508 & 1969 & 1121 & 本文 \\
青海玛多县野牛沟乡 & 316 & 2538 & 938 & 本文 \\
青海贵南县黄沙头 & 399 & 2139 & 1024 & {$[12]$} \\
青海曲麻莱县五道梁乡 & 265 & 1888 & 879 & {$[13]$} \\
青海共和盆地贵南牧场 & 370 & 1929 & 994 & {$[14,15]$} \\
青海果洛州达日县 & 545 & 3462 & 1151 & {$[19]$} \\
\hline
\end{tabular}

a) 所有背景值数据均校正至 2008 年 


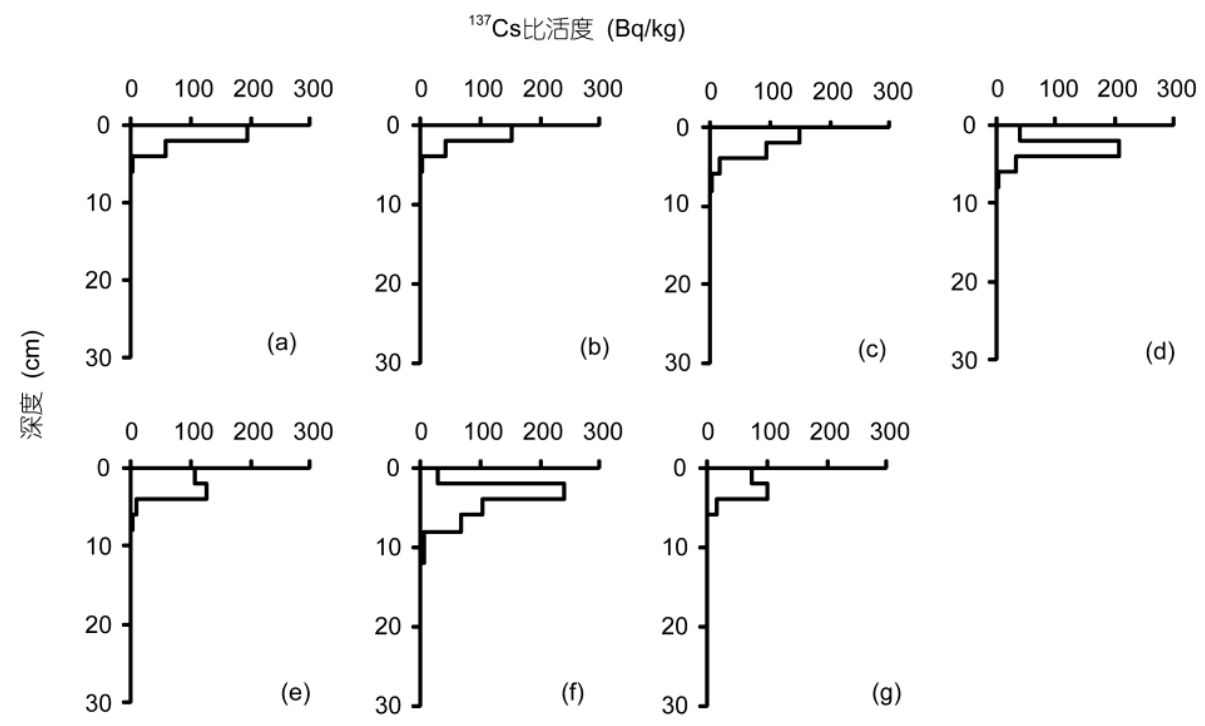

图 2 青海三江源野外采样坡面本底值与坡面分层样 ${ }^{137} \mathrm{Cs}$ 含量剖面分布图

(a) 玉树县玛龙村本底值分层样; (b) 玉树县玛龙村坡面分层样 1; (c) 玉树县玛龙村坡面分层样 2; (d) 称多县珍秦乡本底值分层样; (e) 称多县 珍秦乡坡面分层样; (f) 玛多县野牛沟乡本底值分层样; (g) 玛多县野牛沟乡坡面分层样

随距离坡顶距离的增加略有增强, 侵蚀模数为 471 651 t km $\mathrm{k}^{-2} \mathrm{a}^{-1}$, 受坡度变缓的影响, 比上段末端 的 S1-03 点侵蚀速率明显降低; 坡面下段(S1-07 S1$09)$, 坡度明显减小，侵蚀速率略低于坡面中段，为 $491 \sim 533 \mathrm{t} \mathrm{km}^{-2} \mathrm{a}^{-1}$. 整个坡面上各点侵蚀模数的平均 值为 $464 \mathrm{t} \mathrm{km}^{-2} \mathrm{a}^{-1}$.

珍秦坡面位于长江流域. 坡面草皮层较完整，土 壤为草毡土, 土层较厚, $0 \sim 15 \mathrm{~cm}$ 为根系层. 坡面植 被较好，平均盖度 $70 \%$ ，高度 $1.5 \sim 2.5 \mathrm{~cm}$ ，以小嵩草、 紫花针茅、矮火线草为主，伴生美丽风毛菊、兰石草、 雪白委陵菜等.

由表 3 可见，珍秦坡面各采样点侵蚀强度介于 $518 \sim 1536 \mathrm{t} \mathrm{km}^{-2} \mathrm{a}^{-1}$ 间, 平均为 $875 \mathrm{t} \mathrm{km}^{-2} \mathrm{a}^{-1}$. 侵蚀速 率在坡面植被覆盖度最低的 S2-03 点达到最大, 为 $1536 \mathrm{t} \mathrm{km}^{-2} \mathrm{a}^{-1}$. 植被覆盖度大于 $70 \%$ 的 3 个点 (S2-01, $\mathrm{S} 2-05, \mathrm{~S} 2-06)$ 侵蚀强度差异不大, 平均为 $832 \mathrm{t} \mathrm{km}^{-2}$ $\mathrm{a}^{-1}$, 盖度小于 $70 \%$ 的 2 个测点 $(\mathrm{S} 2-03, \mathrm{~S} 2-07)$ 的土壤侵 蚀强度为 $1174 \mathrm{t} \mathrm{km}^{-2} \mathrm{a}^{-1}$. 坡度大于 $5^{\circ}$ 样点( $\mathrm{S} 2-02$, $\mathrm{S} 2-03, \mathrm{~S} 2-04, \mathrm{~S} 2-05)$ 的平均侵蚀模数为 $890 \mathrm{t} \mathrm{km}^{-2} \mathrm{a}^{-1}$, 小于 $5^{\circ}$ 样点 $(\mathrm{S} 2-01, \mathrm{~S} 2-06, \mathrm{~S} 2-07)$ 的平均侵蚀模数为 $857 \mathrm{t} \mathrm{km}^{-2} \mathrm{a}^{-1}$ ，二者差异不大.

玛多县位于黄河流域. 野牛沟采样坡面草皮层 较完整，土壤为草毡土，根系层厚度为 $15 \sim 20 \mathrm{~cm}$. 坡 面植被覆盖良好，平均盖度 $88 \%$, 高度 $2 \sim 3 \mathrm{~cm}$, 以小
嵩草、矮嵩草、线叶嵩草和荎草为主, 伴生美丽风毛 菊、金露梅、柔软紫苑、马先蒿、委陵菜等.

由表 3 可见, 坡面中部 S3-04 点为堆积点, 堆积 速率 $729 \mathrm{t} \mathrm{km}^{-2} \mathrm{a}^{-1}$, 该点位于坡面上段的凹形坡下部, 受地形转折的影响形成堆积. 包括 S3-04 点的坡面平 均侵蚀模数为 $415 \mathrm{t} \mathrm{km}^{-2} \mathrm{a}^{-1}$; 不包括堆积点的坡面平 均侵蚀模数为 $606 \mathrm{t} \mathrm{km}^{-2} \mathrm{a}^{-1}$ ，前者可代表整个坡面的 净土壤损失强度，后者反映侵蚀作用对坡面土壤侵 蚀的影响程度. 不考虑堆积点, 坡面上植被盖度大于 $90 \%$ 的点 (S3-01, S3-02)侵蚀强度为 $368 \mathrm{t} \mathrm{km}^{-2} \mathrm{a}^{-1}$, 植 被覆盖度 80\% 90\%的点(S3-03, S3-06, S3-07)侵蚀强 度为 $429 \mathrm{t} \mathrm{km}^{-2} \mathrm{a}^{-1}, \mathrm{~S} 3-05$ 点植被覆盖度最低, 为 $75 \%$, 而侵蚀强度最高, 达 $1614 \mathrm{t} \mathrm{km}^{-2} \mathrm{a}^{-1}$.

\section{2 典型高寒草甸坡面土壤侵蚀与植被覆盖度的关系}

通过比较 3 个采样坡面的基本情况(表 1 和 4), 可 以进一步分析土壤侵蚀强度差异的原因. 玛多县野 牛沟坡面, 降水量最低, 且植被覆盖度最高, 尽管平 均坡度最大，但坡面地形呈凹形，造成坡面上有堆积 点存在, 因此野牛沟坡面上平均侵蚀模数最低; 玉树 县玛龙坡面, 坡度最小, 植被平均覆盖度和降水量居 中，相应的平均侵蚀模数也居中; 称多县珍秦坡面降 水量最大, 植被覆盖度最低, 坡面形态与玛龙坡面相 似但坡度稍大，因此，坡面平均侵蚀模数也最大. 由 
表 3 玉树县玛龙村坡面特征、 ${ }^{137} \mathrm{Cs}$ 面积活度与土壤侵蚀模数表 ${ }^{\text {a) }}$

\begin{tabular}{|c|c|c|c|c|c|}
\hline 样点编号 & 距坡顶距离(m) & 坡度 $\left(^{\circ}\right)$ & 植被覆盖度(\%) & ${ }^{137} \mathrm{Cs}$ 面积活度 $\left(\mathrm{Bq} / \mathrm{m}^{2}\right)$ & 侵蚀模数 $\left(\mathrm{t} \mathrm{km}^{-2} \mathrm{a}^{-1}\right)$ \\
\hline S1-01 & 80 & 10 & 高于 $\mathrm{S} 1-02 *$ & $2372.20 \pm 138.19$ & 4 \\
\hline $\mathrm{S} 1-02$ & 180 & 10 & 85 & $2206.75 \pm 108.50$ & 79 \\
\hline $\mathrm{S} 1-03$ & 280 & 10 & 75 & $1541.38 \pm 133.71$ & 945 \\
\hline S1-04 & 380 & 5 & 90 & $1786.38 \pm 121.88$ & 471 \\
\hline S1-05 & 480 & 5 & 85 & $1786.36 \pm 111.60$ & 503 \\
\hline S1-06 & 580 & 5 & 85 & $1676.40 \pm 111.87$ & 651 \\
\hline S1-07 & 680 & 5 & 80 & $1832.19 \pm 130.81$ & 499 \\
\hline S1-08 & 780 & 3 & 85 & $1772.71 \pm 99.65$ & 491 \\
\hline S1-09 & 830 & 3 & 与 $\mathrm{S} 1-08$ 相近* & $1953.29 \pm 135.25$ & 533 \\
\hline $\mathrm{S} 2-01$ & 30 & 5 & 70 & $1477.85 \pm 125.69$ & 836 \\
\hline $\mathrm{S} 2-02$ & 80 & 10 & 与 $\mathrm{S} 2-01$ 相近* & $1487.13 \pm 104.09$ & 769 \\
\hline $\mathrm{S} 2-03$ & 130 & 8 & 62 & $1169.38 \pm 125.21$ & 1536 \\
\hline $\mathrm{S} 2-04$ & 180 & 8 & 与 $\mathrm{S} 2-05$ 相近* & $1631.07 \pm 112.56$ & 518 \\
\hline $\mathrm{S} 2-05$ & 230 & 8 & 70 & $1505.53 \pm 113.64$ & 735 \\
\hline S2-06 & 280 & 5 & 75 & $1405.06 \pm 132.87$ & 924 \\
\hline S2-07 & 330 & 3.5 & 65 & $1574.03 \pm 132.24$ & 811 \\
\hline S3-01 & 20 & 10 & 与 S3-02 相近* & $2417.30 \pm 144.52$ & 374 \\
\hline S3-02 & 55 & 16 & 98 & $2449.78 \pm 149.62$ & 362 \\
\hline S3-03 & 90 & 16 & 85 & $2431.94 \pm 201.80$ & 327 \\
\hline S3-04 & 125 & 18 & 95 & $2814.22 \pm 159.41$ & -729 \\
\hline S3-05 & 160 & 12 & 与 S3-06 相近* & $2057.84 \pm 146.67$ & 1614 \\
\hline S3-06 & 195 & 6 & 80 & $2256.01 \pm 140.45$ & 897 \\
\hline S3-07 & 245 & 2 & 85 & $2516.87 \pm 144.72$ & 62 \\
\hline
\end{tabular}

a)*表示没有实测值

此可见，降水、植被覆盖度和地形因子对坡面土壤侵蚀 的综合影响是显著的. 在坡面尺度上, 坡面侵蚀模数和 植被覆盖度之间存在明显的负相关(表 4 ), 植被覆盖度 越高, 坡面平均侵蚀模数越小, 在 $P<0.01$ 的水平上, $R^{2}=0.986$.

将样点侵蚀速率与坡度、植被覆盖度进行相关分 析, 发现在样点尺度上, 土壤侵蚀速率(剔除 1 个堆 积点)与坡度的关系不显著, 而与植被覆盖度之间具 有较好的负相关 (图 3), 在 $P<0.01$ 的水平上, $R^{2}=0.555$. 表明在影响土壤侵蚀强度的诸多因素中, 植被覆盖 度对高寒草甸侵蚀强度的影响最为明显, 这与高寒 草甸植被的特点有关：高寒草甸地上生物量相对较 小, 但地下生物量较大, 根系密度较大, 集中分布于 表层土壤，相互盘结形成紧实的呈垫状的根系层，对

表 4 三江源区典型高寒草甸土壤侵蚀模数及侵蚀相关因子

\begin{tabular}{ccccc}
\hline 坡面名称 & $\begin{array}{c}\text { 侵蚀模数 } \\
\left(\mathrm{t} \mathrm{km}^{-2} \mathrm{a}^{-1}\right)\end{array}$ & $\begin{array}{c}\text { 平均坡度 } \\
\left({ }^{\circ}\right)\end{array}$ & $\begin{array}{c}\text { 植被平均 } \\
\text { 覆盖度 }(\%)\end{array}$ & $\begin{array}{c}\text { 降水 } \\
(\mathrm{mm})\end{array}$ \\
\hline 玉树县玛龙村 & 464 & 6.2 & 84 & 479 \\
称多县珍秦乡 & 875 & 6.8 & 70 & 508 \\
玛多县野牛沟乡 & 415 & 11.4 & 88 & 316 \\
\hline
\end{tabular}

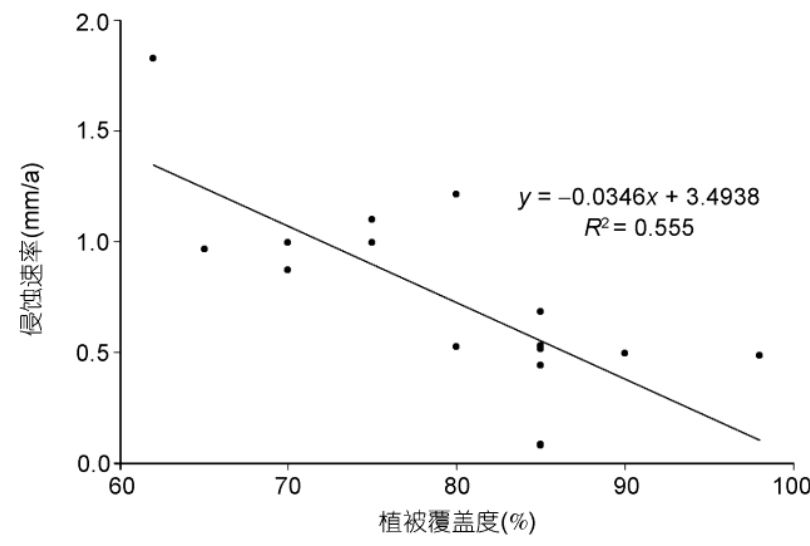

图 3 三江源区典型高寒草甸土壤侵蚀速率与植被覆盖度的 关系

保护土壤免受强度侵蚀具有重要作用. 而植被覆盖度 的高低决定了植被生长状态，进而决定了根系层的紧 实程度, 植被覆盖度越高, 根系层越紧实, 土壤抗侵 蚀能力越强.

\section{4 结论}

本文选择的玉树县玛龙、称多县珍秦和玛多县野 
牛沟 3 个典型的高寒草甸坡面, 草皮层相对完整、植 被覆盖度高、土壤侵蚀的速率较低, 分别为 464,875 和 $415 \mathrm{t} \mathrm{km}^{-2} \mathrm{a}^{-1}$. 根据我国现行的土壤侵蚀分类分级 标准 ${ }^{[28]}$, 玛龙和野牛沟两个坡面属微度侵蚀, 珍秦 坡面属轻度侵蚀.

3 个坡面的土壤类型相同, 在坡面尺度上, 其土壤 侵蚀速率差异受植被覆盖度的影响最显著. 统计分析 表明, 植被覆盖度越高, 坡面的平均侵蚀模数越小; 在 样点的尺度上, 土壤侵蚀速率与坡度的相关关系不显 著, 而与植被覆盖度之间具有较好的负相关关系.
本文 3 个采样坡面均为典型高寒草甸类型, 是三 江源地区最典型和分布面积最广的生态系统类型, 也是三江源地区生态系统服务功能的最主要提供者, 高寒草甸的保育是三江源地区生态功能维护以及“中 华水塔”的最主要方面. 本文得到的高寒草甸坡面土 壤侵蚀与植被覆盖度的关系表明: 具有完整草皮层, 覆盖度较高的原生高寒草甸, 具有土壤保护和防止 水土流失等重要生态功能. 防止三江源地区原生高 寒草甸生态系统的退化, 对于江河源区水土保持功 能的维持具有十分重要的意义.

致谢在野外调查和采样过程中, 得到了中国科学院西北高原与生物研究所李英年研究员、王建雷硕士, 中国科学院地 理科学与资源研究所钟华平副研究员、黄麟博士、赵志平博士、剐龙飞博士, 以及西宁青年旅行社王德善的帮助; 中国地质大学王南萍教授在样品处理与分析上给予了指导与帮助, 在此一并表示衰心感谢.

\section{参考文献}

1 Tamura T, Jacobs D G. Structural implications in cesium sorption. Health Phys, 1960, 6: 391-398

2 Rogowshi A S, Tamura T. Movement of ${ }^{137}$ Cs by runoff, erosion and infiltration on the alluvial captina silt loam. Health Phys, 1965, 11: $1333-3340$

3 Owens P N, Walling D E, He Q P. The behaviour of bomb-derived caesium-137 fallout in catchment soils. J Environ Radioact, 1996, 32: 169-191

4 张信宝, 李少龙, 王成华, 等. 黄土高原小流域泥沙来源的 ${ }^{137} \mathrm{Cs}$ 研究. 科学通报, 1989, 34: 210-213

5 杨明义, 田均良, 刘普灵, 等. ${ }^{137} \mathrm{Cs}$ 示踪研究小流域土壤侵蚀与沉积空间分布特征. 自然科学进展, 2001, 11: 71-75

6 李仁英, 杨浩, 赵晓光, 等. ${ }^{137} \mathrm{Cs}$ 在黄土高原地区土壤侵蚀示踪中的应用研究. 土壤, 2004, 36: 96-98

7 文安邦, 张信宝, 王玉宽, 等. 长江上游 ${ }^{137} \mathrm{Cs}$ 法土壤侵蚀量研究. 水土保持学报, 2002,16: 1-3

8 王玉宽, 文安邦, 张信宝. 长江上游重点水土流失区坡耕地土壤侵蚀的 ${ }^{137} \mathrm{Cs}$ 法研究. 水土保持学报, 2003, 17: 77-80

9 方华军, 杨学明, 张晓平, 等. ${ }^{137} \mathrm{Cs}$ 示踪技术研究坡耕地黑土侵蚀和沉积特征. 生态学报, 2005, 25: 1376-1382

10 庄舜尧, 吴春艳, 杨浩. 红壤侵蚀沉积点 ${ }^{137} \mathrm{Cs}$ 垂直剖面分布特征. 水土保持学报, 2002, 16: 65-67

11 兴励杰, 赵姚阳, 金平华, 等. ${ }^{137} \mathrm{Cs}$ 示踪红壤丘陵区坡地土壤侵蚀的研究一以江西丰城市为例. 长江流域资源与环境, 2004, 13: $562-567$

12 严平, 董光荣, 张信宝, 等. 青海共和盆地土壤风蚀的 ${ }^{137} \mathrm{Cs}$ 法研究 (II ): ${ }^{137} \mathrm{Cs}$ 背景值与风蚀速率测定. 中国沙漠, 2003, 23: 391-397

13 严平, 董光荣, 张信宝, 等. ${ }^{137} \mathrm{Cs}$ 法测定青藏高原土壤风蚀的初步结果. 科学通报, 2000, 45: 199-204

14 张春来, 邹学勇, 董光荣, 等. 干草原地区土壤 ${ }^{137} \mathrm{Cs}$ 沉积特征. 科学通报, 2002, 47: 221-225

15 Zhang C L, Gong J R, Zou X Y, et al. Estimates of soil movement in a study area in Gonghe Basin, north-east of Qinghai-Tibet Plateau. J Arid Environ, 2003, 53: 285-295

16 胡云锋, 刘纪远, 庄大方, 等. 风蚀土壤剖面 ${ }^{137} \mathrm{Cs}$ 的分布及侵蚀速率的估算. 科学通报, 2005, 50: 933-937

17 刘纪远, 齐永青, 师华定, 等. 蒙古高原塔里亚特-锡林郭勒样带土壤风蚀速率的 ${ }^{137} \mathrm{Cs}$ 示踪分析. 科学通报, 2007, 52: 2785-2791

18 齐永青, 刘纪远, 师华定, 等. 蒙古高原北部典型草原区土壤风蚀的 ${ }^{137} \mathrm{Cs}$ 示踪法研究. 科学通报, 2008, 53: 1070-1076

19 李元寿, 王根绪, 王军德, 等. ${ }^{137} \mathrm{Cs}$ 示踪法研究青藏高原草甸土的土壤侵蚀. 山地学报, 2007, 25: 114-121

20 徐新良, 刘纪远, 郡全琴, 等. 30 年来青海三江源生态系统格局和空间结构动态变化. 地理研究, 2008, 27: 829-828

21 Walling D E, Quine T A. Use of Caesium-137 as a Tracer of Erosion and Sedimentation: Handbook for the Application of the Caesium-137 Technique. Exeter: University of Exeter, 1993. 15-34

22 Zhang X B, Li S L, Wang C H, et al. A study of sediment delivery from a small catchment in the loess plateau by the ${ }^{137} \mathrm{Cs}$ method. Chinese Sci Bull, 1990, 35: 37-42

23 Walling D E, He Q. Improved models for estimating soil erosion rates from cesium-137 measurements. J Environ Qual, 1999, 28: $611-622$

24 Zhang X B, Long Y, He X B, et al. A simplified ${ }^{137}$ Cs transport model for estimating erosion rates in undisturbed soil. J Environ Radioact, 2008, 99: $1242-1246$ 
Zapata F. Handbook for the Assessment of Soil Erosion and Sedimentation Using Environmental Radionuclides. London: Kluwer Academic Publishers, 2002. 219

26 伏介雄，张信宝，齐永青，等。无侵蚀非农耕地土壤 ${ }^{137} \mathrm{Cs}$ 深度分布人渗过程模型。核技术, 2006, 29: 189-193

27 齐永青, 张信宝, 贺秀斌, 等. 中国 ${ }^{137} \mathrm{Cs}$ 本底值区域分布研究. 核技术, 2006, 29: 42-50

28

中华人民共和国水利部.SL190-96. 土壤侵蚀分类分级标准. 北京：中国水利水电出版社, 1997

- 动 态・

\section{中国最古老文字的复原}

甲骨文是刻写在龟甲和兽骨上的文字, 流行于我国古 代的商朝. 人们印象中的甲骨文字形都是笔画劲直. 然而 这些字形一般是通过对甲骨拓片字形进行手工修复得到 的, 费时费力. 徐州师范大学语言研究所的科研人员利用 计算机技术实现了对甲骨拓片字形的复原.

这项题为 “基于泊松分布与分形几何的甲骨拓片字形 复原方法”的研究成果于今年 1 月发表在《中国科学 信息 科学》第 1 期(http://www.scichina.com:8083/sciF/CN/volumn/ volumn_6096.shtml)上. 徐州师范大学语言研究所杨亦鸣 教授领导的学术团队进行了该项研究.

自 1899 年王懿荣发现甲骨文以来已经有一百多年了. 作为我国迄今发现的最早的一种成熟文字系统, 甲骨文具 有极其重要的学术价值和文化遗产保护价值. 现在已出土 的甲骨数量众多, 据不完全统计有 15 万片左右, 而且还有 一些新的甲骨不断地被发现. 目前已出土的甲骨散失在世 界各地, 由于数量众多、容易损坏、极其宝贵等原因, 人 们一般不容易接触到这些甲骨. 现已刊行的甲骨文著录书 籍数量众多, 查阅非常方便, 但是这些著录书籍一般发行 量较小、价格昂贵, 不是所有的读者都有能力购买得起, 以至于很多读者不能方便地接触到这些资料. 这些都不利 于甲骨文的广泛传播, 不利于对它进行深人研究.

近年来，由于信息技术的快速发展，特别是计算机的 日益普及和网络的快速发展, 人们希望借助于计算机和网 络提高甲骨文的传播速度和利用效率. 将龟甲和兽骨上的 文字转换为计算机可以识别和处理的字符, 实现在网络上 的传播, 这就是对甲骨文的数字化处理. 然而, 甲骨文是 书写在龟甲和兽骨上的文字，经历了几千年的岁月沧桑， 加上发掘和运输的污损, 作为书写载体的龟甲和兽骨已腐 蚀损坏严重, 因而造成了甲骨上的字形的边缘非常模糊, 呈现出明显的锯齿形态, 已经不具备甲骨文字形最初的面 貌. 以这样污损严重的甲骨为原型拓出来的字形必然存在
噪声点和字形模糊的问题. 由于字形边缘已经变得非常模 糊, 对于甲骨文字形的识读和研究带来极大不便, 因而非常 需要对甲骨拓片上的字形进行复原. 目前, 高质量的甲骨文 字形通常都是通过手工获取的, 需要具有丰富经验的专业 人员使用图像处理软件对甲骨拓片字形图像进行手工修复 处理, 去除字形图像上的噪声点, 对因腐蚀造成的锯齿状边 缘进行平滑, 非常耗时耗力, 而且修复效果也不尽如人意.

杨亦鸣带领的研究小组分析发现, 甲骨拓片上的噪声 点符合数学统计上的泊松分布特征, 绝大多数噪声区域的 面积都很小, 区域面积大的噪声点为数很少. 利用这一统 计特征可以把甲骨拓片上的被污染的噪声区域去除, 保留 甲骨文字形笔划区域. 清除噪声点后的甲骨拓片字形边缘 呈现锯齿形态, 仍然不具备甲骨文字形的原始面貌. 分析 发现, 字形边缘可以近似看作分形特征. 通过对字形边缘 进行压缩变换来对字形边缘进行平滑, 通过计算边缘的分 形维数来控制字形边缘的平滑程度, 最终平滑字形图像边 缘因腐蚀所造成的凹凸形态，恢复甲骨文字形的原貌.

通过利用计算机技术实现甲骨拓片字形的修复，大大 减轻了人工修复甲骨文字形的劳动强度. 通过对甲骨文字 形进行计算机辅助复原, 将模糊的甲骨文字形恢复原貌, 方便甲骨文研究学者对甲骨文字形进行辨识和解读, 以便 更好地了解商代的经济、文化、社会生活状况, 为夏商周 断代工程提供更进一步的文献资料, 促进我国夏商周断代 研究的推进. 这一研究成果已申请国家发明专利.

徐州师范大学语言研究所是专门从事语言学及应用 语言学研究的学术研究机构, 建有语言科学与神经认知工 程江苏省重点实验室.

该项研究得到了国家自然科学基金(30740040)、教育部 人文社会科学基金(YJC740032)、江苏省“333”高层次人才 培养工程科研基金(苏教办师[2008]46 号)和江苏省社会科 学基金(09YYB011)的资助. 